\title{
Efecto antibacteriano de extractos etanólicos de plantas utilizadas en la tradiciones culinarias andinas sobre microorganismos de la cavidad bucal
}

\author{
Antibacterial effect of ethanolic extracts from plants utilized in the Andes culinary traditions against \\ microorganisms of the oral cavity \\ Erika Pimentel Ramirez ${ }^{1, a}$, Diana Castillo Andamayo ${ }^{1, b}$, Martin Quintana Del Solar ${ }^{1, c}$, Dora Maurtua Torres ${ }^{2, d}$, \\ León Villegas Vílchez ${ }^{3, d}$, Camilo Díaz Santisteban ${ }^{3, d}$.
}

\section{RESUMEN}

Objetivos: Determinar la actividad antibacteriana in vitro del extracto etanólico de Origanum vulgare (orégano), Tagetes elliptica (chincho) y del Tagetes minuta (huacatay) comparado con Clorhexidina al $0.12 \%$ y Colgate Plax frente a cepas de Lactobacillus acidophilus ATCC 43121 y Porphyromonas gingivalis ATCC 33277. Material y métodos: Se evaluó la actividad antimicrobiana mediante el método de Difusión en Agar, Mínima Concentración Inhibitoria y Técnica Pour Plate (Técnica de Vertido en Placa). El diseño del estudio fue de tipo experimental in vitro de corte transversal. El análisis estadístico univariado y bivariado se hizo en el programa SPSS 17.0. Resultados: Se determinó que la actividad antibacteriana de las sustancias experimentales para la cepa Lactobacillus acidophilus ATCC 43121 fue el extracto etanólico del orégano al 100\% tuvo un promedio en los halos de inhibición de 18,43 $\pm 3,96 \mathrm{~mm}$, el extracto etanólico del chincho al $100 \%$ de $20,5 \pm 2,99 \mathrm{~mm}$, clorhexidina al 0,12\% de 21,3 $\pm 0,38 \mathrm{~m}$ y Colgate Plax 14,93 $\pm 0,84 \mathrm{~mm}$. Frente a la cepa Porphyromonas gingivalis ATCC 33277:el extracto etanólico de chincho 100\% tuvo un promedio en los halos de inhibición de 16.27 $\pm 2,67$, el extracto etanólico de orégano $100 \%$ tuvo un promedio en los halos de inhibición de $25,86 \pm 1,18 \mathrm{~mm}$, el extracto etanólico del huacatay $100 \%$ de $24,49 \pm 3,21 \mathrm{~mm}$, con clorhexidina al $0,12 \%$ de $19,59 \pm 0,48 \mathrm{~mm}$ y con Colgate Plax 14,29 $\pm 0,3 \mathrm{~mm}$. La MIC del extracto etanólico del chincho frente a la cepa Lactobacillus acidophilus ATCC 43121 fue de $125 \mathrm{mg} / \mathrm{mL}$, encontrando la medida de los halos de inhibición de 10,33 mm. Conclusiones: Existe actividad antibacteriana in vitro del extracto etanólico de Origanum vulgare (orégano), Tagetes elliptica (chincho) comparado con Clorhexidina al 0,12\% y Colgate Plax frente a cepas de Lactobacillus acidophilus ATCC 43121 y Porphyromonas gingivalis ATCC 33277; asimismo el Tagetes minuta (huacatay) tiene efectividad con esta última cepa bacteriana.

Facultad de Estomatología, Universidad Peruana Cayetano Heredia. Lima, Perú.

Departamento de Microbiología, Universidad Peruana Cayetano Heredia. Lima, Perú.

Departamento de Ciencias Farmacéuticas, Universidad Peruana Cayetano Heredia. Lima, Perú.

Residente del Programa de Especialización en Rehabilitación Oral.

Especialista en Rehabilitación Oral.

Coordinador adjunto del Área de Rehabilitación Oral.

Docente. 
PALABRAS CLAVE: Agente antibacteriano, extractos de plantas, cavidad bucal, Origanum, Tagetes.

\section{SUMMARY}

Objectives: to determine the in vitro antibacterial activity of the ethanolic extract from Origanum vulgare (oregano), Tagetes elliptica (chincho) and Tagetes minuta (huacatay) compared with clorhexidine $0.12 \%$ and Colgate Plax against Lactobacillus acidophilus ATCC 43121 and Porphyromonas gingivalis ATCC 33277.

Materials and Methods: Antimicrobial activity was evaluated by agar diffusion method, minimum inhibitory concentration (MIC) and pour plate technique. The study design was experimental in vitro cross sectional. The univariate and bivariate statistical analysis were done in SPSS 17.0.

Results: it was found that the antibacterial activity of experimental substances against Lactobacillus acidophilus ATCC 43121 was: the $100 \%$ oregano ethanolic extract had an inhibition zone average of $18.43 \pm 3.96 \mathrm{~mm}$, the $100 \%$ chincho ethanolic extract of $20.5 \pm 2.99 \mathrm{~mm}$, clorhexidine $0.12 \% 21.3 \pm 0.38 \mathrm{~mm}$ and Colgate Plax 14.93 $\pm 0.84 \mathrm{~mm}$. For Porphyromonas gingivalis ATCC 33277: the 100\% chincho ethanolic extract had an inhibition zone average of $16.27 \pm 2.67 \mathrm{~mm}$, the $100 \%$ oregano ethanolic extract had an inhibition zone average of 25.86 $\pm 1.18 \mathrm{~mm}$, the $100 \%$ huacatay ethanolic extract of $24.49 \pm 3.21 \mathrm{~mm}$, clorhexidine $0.12 \%$ of $19.59 \pm 0.48 \mathrm{~mm}$ and Colgate Plax $14.29 \pm 0.3 \mathrm{~mm}$. The MIC of the chincho ethanolic extract against Lactobacillus acidophilus ATCC 43121 was $125 \mathrm{mg} / \mathrm{mL}$, finding inhibition zones of $10.33 \mathrm{~mm}$.

Conclusions: there is an effective in vitro antibacterial activity of the Origanum vulgare (oregano) and Tagetes elliptica (chincho) ethanolic extracts compared to clorhexidine $0.12 \%$ and Colgate Plax against Lactobacillus acidophilus ATCC 43121 and Porphyromonas gingivalis ATCC 33277, however, the Tagetes minuta (huacatay) is effective only against Porphyromonas gingivalis ATCC 33277.

\section{KEY WORDS: antibacterial agents, plant extracts, mouth, Origanum, Tagetes.}

\section{INTRODUCCION}

La caries dental es una enfermedad ampliamente extendida en el mundo, por lo que ha sido y sigue siendo la enfermedad más frecuente del hombre moderno. Dentro de los factores principales que influyen en la prevalencia de la caries dental son la presencia de microorganismos. Las bacterias que se relacionan con mayor frecuencia con el inicio y desarrollo de la caries son: estreptococos del grupo mutans, Lactobacillus sp. , y Actinomyces sp., estos pueden ser aislados a partir de placa dental supra y subgingival y en saliva (1).

Las enfermedades periodontales, son procesos que afectan a los tejidos de soporte dentario y que están muy relacionados con la acumulación de placa y cálculo dental, así como también con la presencia de microorganismos patógenos, siendo las bacterias anaerobias gram negativas, las principalmente involucradas en esta entidad. Entre las más comúnmente relacionadas tenemos a las Porphyromonas gingivalis, y Fusobacterium nucleatum. Diversos autores señalan que el poder patógeno de esta bacteria es la colonización, destrucción del tejido periodontal y evasión de las defensas del hospedero, tiene relación con un gran número de factores de virulencia (2-4).

Para la eliminación de éstas bacterias existen antimicrobianos (antibacterianos, habitualmente conocidos como antibióticos), así como también los que actúan sobre los virus, hongos y parásitos. La medicina natural, a partir de las plantas y sus propiedades antimicrobianas, últimamente ha recibido mucha atención de los científicos, ya que presentan actividad antibacteriana capaz de combatir a agentes patógenos como el Staphylococcus aureus, Streptococcus mutans y Porphyromonas gingivalis, siempre que se les considere como coadyuvantes de un control mecánico de la biopelícula por medios físicos (cepillado, uso de hilo dental) (5).

Tras diversas investigaciones se ha comprobado que el Origanum vulgare (orégano), Tagetes elliptica (chincho) y Tagetes minuta (huacatay) son plantas naturales que tienen un buen efecto antimicrobiano, antioxidante y antifúngico contra microorganismos (6-8).

El propósito de este estudio es evaluar el efecto de los extractos etanólicos del Origanum vulgare (oré- 
gano), del Tagetes elliptica (chincho) y del Tagetes minuta (huacatay) frente a bacterias que participan en la progresión de la caries dental (Lactobacillus acidophilus) y enfermedad periodontal (Porphyromonas gingivalis).

\section{MATERIAL Y MÉTODOS}

El presente estudio, de tipo experimental in vitro y corte transversal, tuvo como tamaño muestral 7 placas agar que contenían las cepas Lactobacillus acidophilus ATCC 43121, y Porphyromonas gingivalis ATCC 33277. Previa a la ejecución del trabajo de investigación se contó con la aprobación del Comité Institucional de Ética de la Universidad Peruana Cayetano Heredia.

Los procedimientos fueron los siguientes:

1) Recolección de las hojas de Origanum vulgare (orégano) y Tagetes elliptica (chincho), Tagetes minuta (huacatay) $(6,9)$

Se realizó la recolección de las hojas en el mismo lugar de procedencia (Huaraz ubicado a $3052 \mathrm{msnm}$ ) con la ayuda de una persona de la misma zona, que tenía experiencia con esta planta. Se recolectaron aproximadamente $5 \mathrm{Kgs}$. de hojas de Origanum vulgare (orégano), Tagetes elliptica (chincho) y Tagetes minuta (huacatay).

El transporte de las hojas desde el lugar de recolección, hacia el Laboratorio de Investigación y desarrollo (LID) de la Universidad Peruana Cayetano Heredia (UPCH), se realizó, en bolsas de sacos harineros limpios para evitar la contaminación y asegurar la ventilación, evitando la putrefacción en pocas ho- ras. Los $5 \mathrm{kgs}$. de hojas frescas recolectadas fueron puestas a secar a temperatura ambiente en la zona de extracción $\left(30^{\circ} \mathrm{C}\right.$ aprox.) sin exposición solar, para su deshidratación (Figura 1).

2) Obtención del extracto de Origanum vulgare (orégano), Tagetes elliptica (chincho), Tagetes minuta (huacatay) $(9,10)$

Los $5 \mathrm{Kgs}$. de hojas secas fueron extendidos en una mesa y se seleccionaron las hojas libres de hongos y sin maltratos. Luego se procedió a pulverizar en una trituradora con el fin de obtener $770 \mathrm{~g}$. de hoja triturada; se envasó en un recipiente de vidrio donde se le agregó 1 litro de etanol químicamente puro (QP) por cada 100 g. de hoja triturada. Se almacenó a temperatura ambiente por un lapso de 20 días para su maceración.

Luego se filtró usando un papel filtro Whatman $\mathrm{N}^{\circ} 40$; los remanentes se dejaron en maceración por 8 días y luego se filtraron con la misma técnica; esto nos permitió extraer los componentes en su mayor cantidad posible. Posteriormente fue sometido a un rotavapor a $40^{\circ} \mathrm{C}$ y vacío para extraer el etanol. Después de este proceso, aun quedaron residuos de etanol dentro del extracto, del cual tenía que ser eliminado totalmente, para ello se utilizó una cámara al vacío con la misma temperatura, obteniendo de ésta manera un extracto etanólico confiable (Figura 2).

Con la finalidad de afirmar si los extractos etanólicos de las plantas en estudio cumplían con los requisitos de esterilidad, se realizó la prueba de esterilidad con el medio líquido de tioglicolato, el cual sirve principalmente para el cultivo de bacterias anaerobias; sin

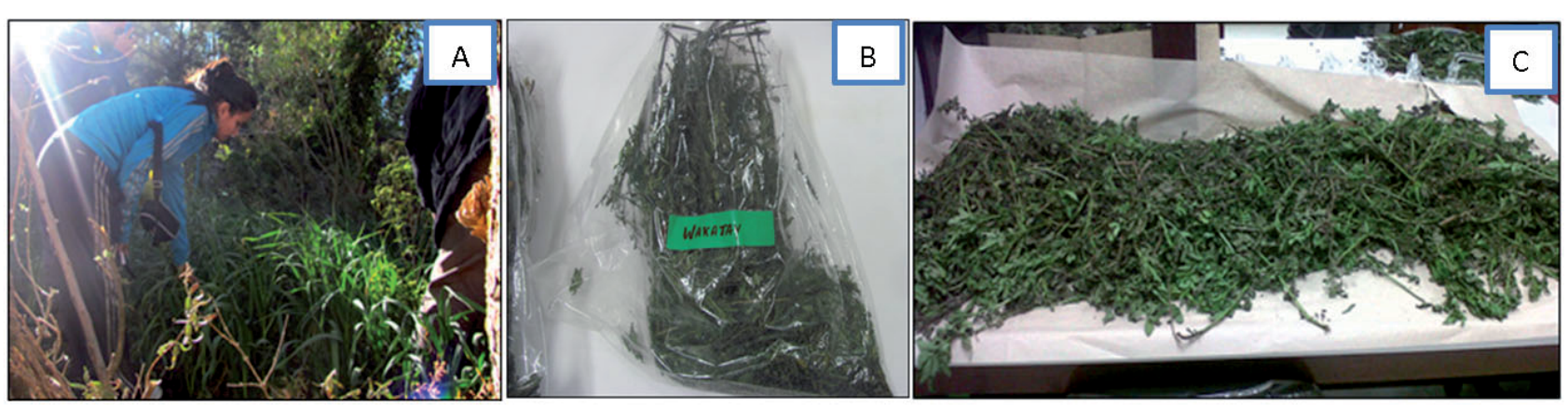

Figura 1.A. Identificación de plantas de estudio, B. Bolsas de recolección y transporte de muestra, C.Hojas tendidas puestas a secar. 


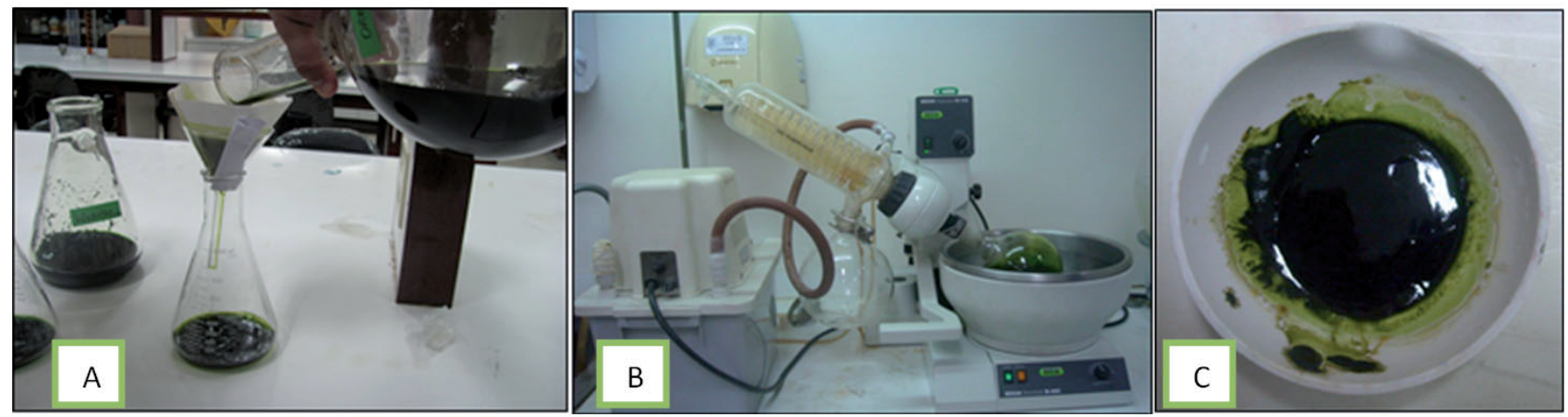

Figura 2.A. Filtración con papel filtro Whatman $\mathrm{N}^{\circ} 40$, B.Rotavapor a $40^{\circ} \mathrm{C}, \mathrm{C}$. Extracto etanólico

embargo, también detecta bacterias aerobias.

Se examinaron los medios en busca de evidencias macroscópicas de crecimiento microbiano, que se evidencian cuando se enturbian los medios de cultivo; sin embargo, como no se hallaron evidencias de crecimiento microbiano, el producto examinado cumplió con la prueba de esterilidad.

\section{3) Evaluación de la actividad antibacteriana}

\section{-Difusión en Agar:}

Se procedió a realizar la siembra de este inóculo en las placas de Petri conteniendo los agares correspondientes por cepa (de $4 \mathrm{~mm}$ de grosor) usando un hisopo, el cual se pasó de manera uniforme sobre la superficie del agar. Inmediatamente se colocó 0,5 g (500 mg) en el centro de la placa Petri de los extractos puros de Origanum vulgare (orégano), Tagetes elliptica (chincho) y Tagetes minuta (huacatay) y; las soluciones experimentales que actúan como control (Agua destilada, BHI, Clorhexidina 0,12\%, Colgate Plax) se aplicaron en cantidades de 10 ul en discos de papel filtro Whatman $\mathrm{N}^{\circ} 3$ (6mm de diámetro) con ayuda de una micropipeta (Marca Merck) (Figura 3).
-Mínima Concentración Inhibitoria (MIC):

Para esta parte del ensayo, se utilizaron 6 tubos para poder obtener 6 concentraciones para cada extracto etanólico.

Como no había una turbidez definida debido a la pigmentación de los extractos etanólicos, se realizó un pasaje de $10 \mu 1$ de muestra de cada uno de los tubos con ayuda de un instrumento sobre las placas Petri que contenían los agares correspondientes por cepa (de $4 \mathrm{~mm}$ de grosor). Con este método observacional se determinó la Mínima Concentración Inhibitoria (MIC), definida como la mínima concentración de extracto etanólico que sea capaz de inhibir el crecimiento bacteriana (Figura 4).

-Técnica Pour Plate (Técnica de vertido en placa) Una vez que se determinó la mínima concentración inhibitoria (MIC), se utilizó una técnica llamada Pour Plate que nos permitió cuantificar el tamaño de los halos de inhibición de aquellas concentraciones que mostraron actividad antibacteriana en el método de dilución en tubos.

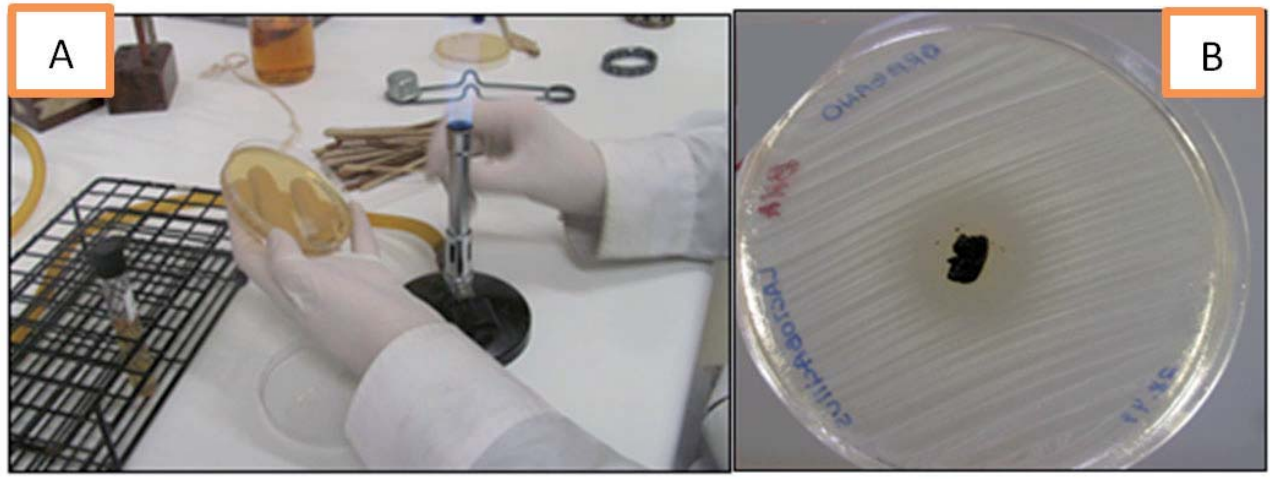

Figura 3. A. Siembra de Inóculo, B. Aplicación de $1 \mathrm{~g}$ de extracto etanólico al centro de Placa Petri 


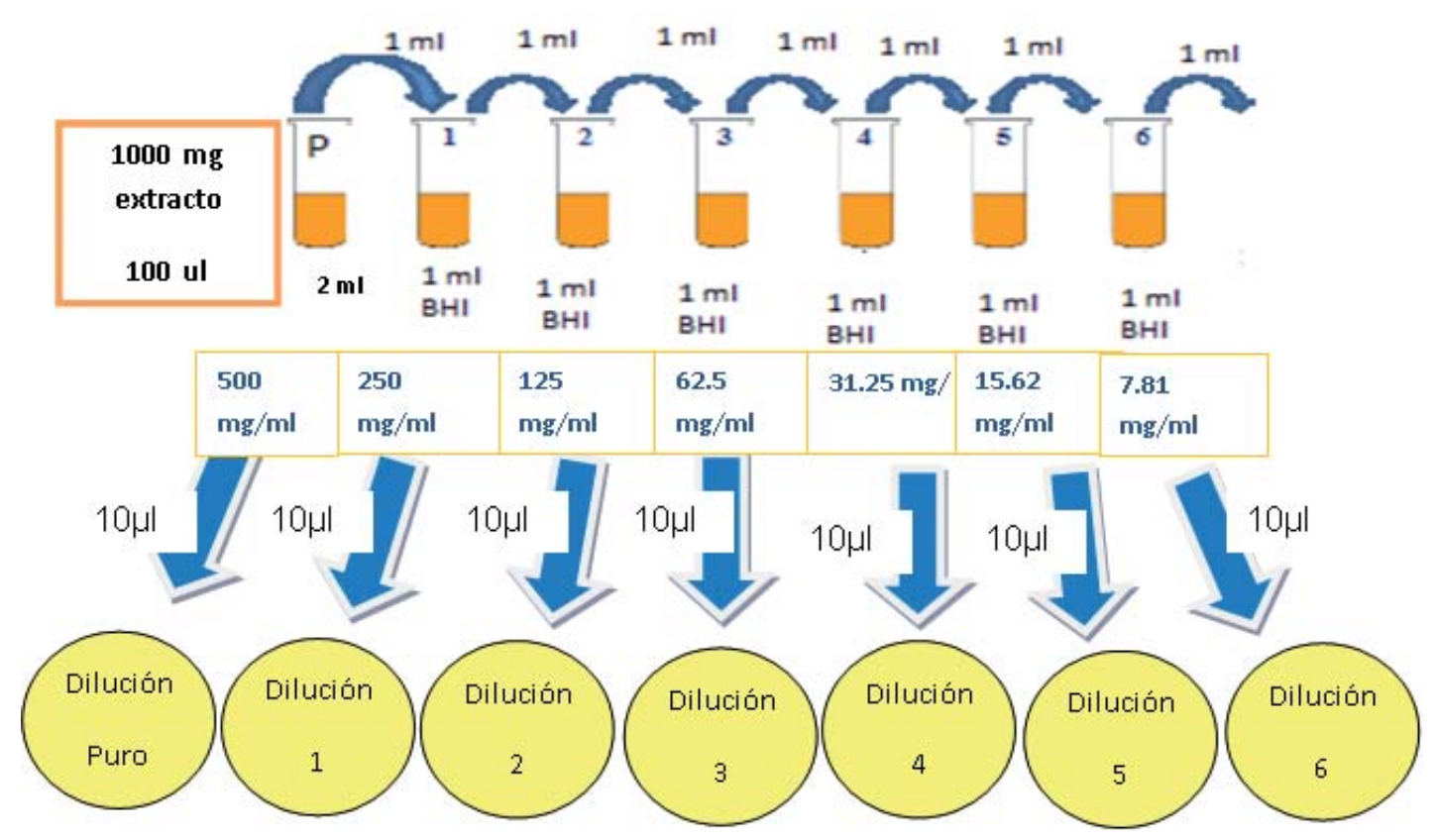

Figura 4. Cultivo de la MIC en placas Petri.

Para esta parte del ensayo, se utilizaron 4 tubos para poder obtener las concentraciones que mostraron inhibición y aquella concentración que no inhibió el crecimiento bacteriano. Se dividió la placa en cuatro cuadrantes donde una vez gelificado el agar se preparó un pozo en cada cuadrante con sacabocado estéril, donde se colocaron $100 \mu \mathrm{l}$ del extracto etanólico en sus distintas diluciones. Se preparó un pozo para cada control positivo (Colgate Plax, Perio-Aid) y controles negativos (BHI, Agua destilada).Cada prueba con los diferentes extractos etanólicos se rea- lizó por triplicado. Se procedió a continuación con la incubación en jarras de anaerobiosis para Porphyromonas gingivalis por 96 horas (4 días) a $37^{\circ} \mathrm{C}$ mientras que para Lactobacillus acidophilus el periodo de incubación es de 48 horas a la misma temperatura en incubadora (Fisher Scientific ${ }^{\odot}$ ). Luego de la incubación se procedió a la medición de cada halo inhibitorio correspondiente a los pozos de las distintas diluciones con calibrador pie de rey (Figura 5).
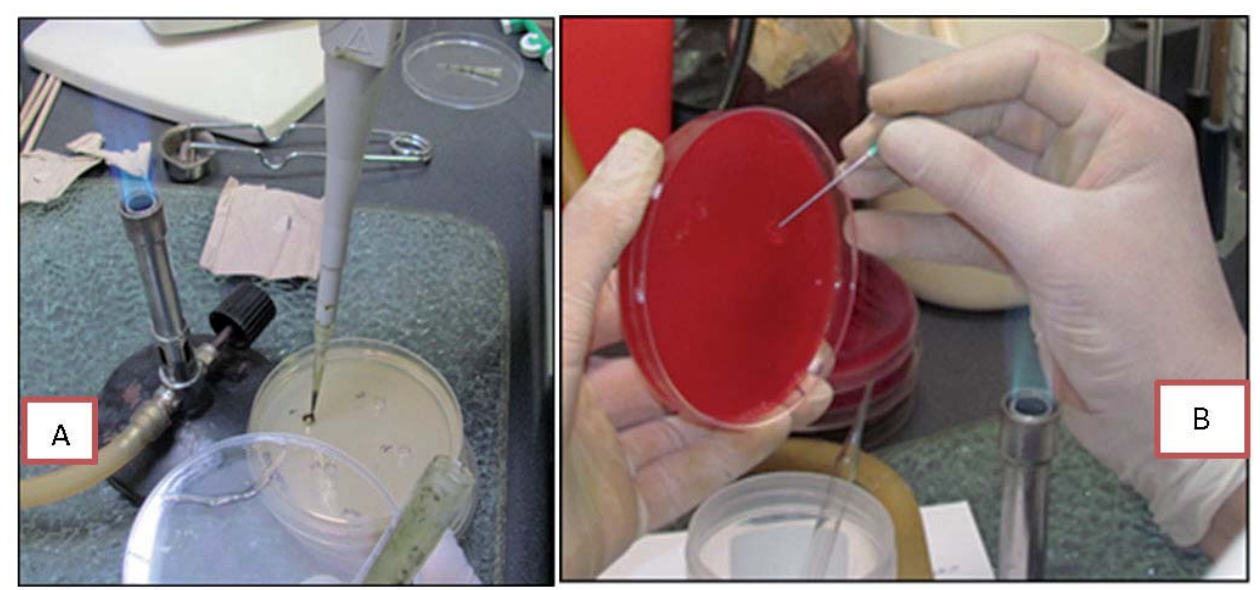

Figura 5. A. Técnica de vertido en placa (Pour Plate), B.Perforación de pozos con aguja estéril. 


\section{RESULTADOS}

Cuando se evalúo la mínima concentración inhibitoria del extracto etanólico del chincho frente a la cepa Lactobacillus acidophilus ATCC 43121 se obtuvo un MIC de $125 \mathrm{mg} / \mathrm{mL}$, encontrando la medida de los halos de inhibición de 10,33 mm., (Tabla 1).

Tabla 1. Concentración mínima inhibitoria del Tagetes elliptica (chincho) frente a Lactobacillus acidophilus ATCC 43121

\begin{tabular}{llll}
\hline $\begin{array}{l}\text { Concentración de } \\
\text { Chincho }\end{array}$ & $\mathrm{N}$ & Media $(\mathrm{mm})$ & Desv Stand \\
\hline $500 \mathrm{mg} / \mathrm{ml}$ & 6 & 13,83 & 0,41 \\
$250 \mathrm{mg} / \mathrm{ml}$ & 6 & 12,67 & 0,52 \\
$125 \mathrm{mg} / \mathrm{ml}$ & 6 & 10,33 & 0,26 \\
$62.5 \mathrm{mg} / \mathrm{ml}$ & 6 & 0 & 0 \\
\hline
\end{tabular}

La actividad antibacteriana del extracto etanólico del Origanum vulgare (orégano) en diferentes concentraciones frente a la cepa Porphyromonas gingivalis ATCC 33277 se presentó de la siguiente manera; el extracto etanólico del orégano a $500 \mathrm{mg} / \mathrm{mL}$ tuvo un promedio de halo de inhibición de $16,47 \pm 1,73$ $\mathrm{mm}$, el extracto etanólico de orégano a $250 \mathrm{mg} / \mathrm{mL}$ de $12,78 \pm 0,42 \mathrm{~mm}$, el extracto etanólico de orégano a $125 \mathrm{mg} / \mathrm{mL}$ de $11,05 \pm 0,39 \mathrm{~mm}$ y el extracto etanólico de orégano a $62,5 \mathrm{mg} / \mathrm{mL}$ de $8,75 \pm 0,27 \mathrm{~mm}$. A medida que la concentración del extracto etanólico de orégano disminuye la medición de los halos de inhibición también disminuyó (Tabla 2).

Tabla 2. Determinación de los halos inhibitorios del Origanum vulgare (orégano) en concentraciones de $500 \mathrm{mg} /$ $\mathrm{ml}, 250 \mathrm{mg} / \mathrm{ml}, 125 \mathrm{mg} / \mathrm{ml}, 62,5 \mathrm{mg} / \mathrm{ml}$ frente a Porphyromonas gingivalis ATCC 3327.

\begin{tabular}{llll}
\hline $\begin{array}{l}\text { Concentración de } \\
\text { orégano }\end{array}$ & $\mathrm{N}$ & Media $(\mathrm{mm})$ & Desv Stand \\
\hline $500 \mathrm{mg} / \mathrm{ml}$ & 6 & 16,47 & 1,73 \\
$250 \mathrm{mg} / \mathrm{ml}$ & 6 & 12,78 & 0,42 \\
$125 \mathrm{mg} / \mathrm{ml}$ & 6 & 11,05 & 0,39 \\
$62.5 \mathrm{mg} / \mathrm{ml}$ & 6 & 8,75 & 0,27 \\
\hline
\end{tabular}

La actividad antibacteriana del extracto etanólico del Tagetes elliptica (chincho) en diferentes concentraciones frente a la cepa Porphyromonas gingivalis ATCC 33277 se presentó de la siguiente manera; el extracto etanólico de chincho a $500 \mathrm{mg} / \mathrm{mL}$ tuvo un promedio de halo de inhibición de $14,23 \pm 0,98 \mathrm{~mm}$, el extracto etanólico de chincho a $250 \mathrm{mg} / \mathrm{mL}$ de $12,03 \pm 1,28 \mathrm{~mm}$, el extracto etanólico de chincho a $125 \mathrm{mg} / \mathrm{mL}$ de $10,46 \pm 1,11 \mathrm{~mm}$ y el extracto etanólico de chincho a $62,5 \mathrm{mg} / \mathrm{mL}$ de $8,46 \pm 0,81 \mathrm{~mm}$. A medida que la concentración del extracto etanólico de chincho disminuye la medición de los halos de inhibición también disminuyó (Tabla 3).

Tabla 3.Determinación de los halos inhibitorios del Tagetes elliptica (chincho) en concentraciones de $500 \mathrm{mg} / \mathrm{ml}$, $250 \mathrm{mg} / \mathrm{ml}, 125 \mathrm{mg} / \mathrm{l}$

\begin{tabular}{lccc}
\hline $\begin{array}{c}\text { Concentración de } \\
\text { chincho }\end{array}$ & $\mathrm{n}$ & Media (mm) & Desv Stand \\
\hline $500 \mathrm{mg} / \mathrm{ml}$ & 6 & 14,23 & 0,98 \\
$250 \mathrm{mg} / \mathrm{ml}$ & 6 & 12,03 & 1,28 \\
$125 \mathrm{mg} / \mathrm{ml}$ & 6 & 10,46 & 1,11 \\
$62.5 \mathrm{mg} / \mathrm{ml}$ & 6 & 8,46 & 0,81 \\
\hline
\end{tabular}

La actividad antibacteriana del extracto etanólico del Tagetes minuta (huacatay) en diferentes concentraciones frente a la cepa Porphyromonas Gingivalis ATCC 33277 se presentó de la siguiente manera; el extracto etanólico de chincho a $500 \mathrm{mg} / \mathrm{mL}$ tuvo un promedio de halo de inhibición de $15.96 \pm 0.78 \mathrm{~mm}$, el extracto etanólico de chincho a $250 \mathrm{mg} / \mathrm{mL}$ de $10.28 \pm 0.59$ $\mathrm{mm}$, el extracto etanólico de chincho a $125 \mathrm{mg} / \mathrm{mL}$ de $8.78 \pm 0.63 \mathrm{~mm}$ y el extracto etanólico de chincho a $62.5 \mathrm{mg} / \mathrm{mL}$ de $7.96 \pm 0.82 \mathrm{~mm}$. A medida que la concentración del extracto etanólico de chincho disminuye la medición de los halos de inhibición también disminuyó. (Tabla 4)

Tabla 4. Determinación de los halos inhibitorios del Tagetes minuta (huacatay) en concentraciones de $500 \mathrm{mg} / \mathrm{ml}$, $250 \mathrm{mg} / \mathrm{ml}, 125 \mathrm{mg} / \mathrm{l}$

\begin{tabular}{llll}
\hline $\begin{array}{l}\text { Concentración de } \\
\text { huacatay }\end{array}$ & $\mathrm{n}$ & Media $(\mathrm{mm})$ & Desv Stand \\
\hline $500 \mathrm{mg} / \mathrm{ml}$ & 6 & 15,96 & 0,78 \\
$250 \mathrm{mg} / \mathrm{ml}$ & 6 & 10,28 & 0,59 \\
$125 \mathrm{mg} / \mathrm{ml}$ & 6 & 8,78 & 0,63 \\
$62.5 \mathrm{mg} / \mathrm{ml}$ & 6 & 7,96 & 0,82 \\
\hline
\end{tabular}

Al comparar los halos de inhibición de las sustancias experimentales entre cepas de Lactobacillus acidophilus ATCC 43121 y Porphyromonas gingivalis ATCC 33277 se observó que tienen diferencias estadísticamente significativas con un $\mathrm{p}<0,05$ (Tabla 5). 
Tabla 5. Comparación de los halos inhibitorios de las sustancias experimentales frente al Lactobacillus acidophilus ATCC 43121y Porphyromonas gingivalis ATCC 33277

\begin{tabular}{llll}
\hline Sustancias experimentales & N & Media (mm) & Valor de p \\
\hline Chincho (100\%) & & & \\
$\quad$ Lactobacillus acidophilus & 7 & 20,5 & $0,0177(* *)$ \\
$\quad$ Porphyromonas gingivalis & 7 & 16,27 & \\
Orégano (100\%) & & & $0,002(*)$ \\
$\quad$ Lactobacillus acidophilus & 7 & 18,43 & \\
$\quad$ Porphyromonas gingivalis & 7 & 25,86 & $0,0008(* *)$ \\
Huacatay (100\%) & & & \\
$\quad$ Lactobacillus acidophilus & 7 & 0 & $0,0009(* *)$ \\
$\quad$ Porphyromonas gingivalis & 7 & 24,49 & \\
Clorhexidina 0.12\% & & & \\
$\quad$ Lactobacillus acidophilus & 7 & 21,36 & \\
$\quad$ Porphyromonas gingivalis & 7 & 19,59 & \\
Colgate plax & & & \\
$\quad$ Lactobacillus acidophilus & 7 & 14,39 & \\
$\quad$ Porphyromonas gingivalis & 7 & 14,29 & \\
T student (*) & & & \\
U de Mann Whitney (**) & & & \\
\hline
\end{tabular}

$\mathrm{p}=0.0177$

Cuando se realizó las comparaciones se halló que la acción antibacteriana del extracto etanólico del chincho (100\%) frente al Lactobacillus acidophilus presentó mayor efecto comparado con la Porphyromonas gingivalis, siendo esta diferencia estadísticamente significativa $(\mathrm{p}<0,05)$; la acción antimicrobiana del extracto etanólico del orégano (100\%) frente al Lactobacillus acidophilus fue menor que la Porphyromonas gingivalis, siendo esta diferencia estadísticamente significativa $(\mathrm{p}<0,05)$. La acción antibacteriana del huacatay $(100 \%)$ presentó acción antibacteriana frente a la Porphyromonas gingivalis mas no en Lactobacillus acidophilus ; La acción antibacteriana de la clorhexidina al 0,12\% frente al Lactobacillus acidophilus fue mayor al compararla con Porphyromonas gingivalis, siendo esta diferencia estadísticamente significativa $(\mathrm{p}<0,05)$ y Colgate plax frente al Lactobacillus acidophilus al compararlo con Porphyromonas gingivalis, no es estadísticamente significativa $(\mathrm{p}>0,05)$ (Tabla 5).

\section{DISCUSION}

La especie Origanum vulgare (orégano) dentro de sus compuestos químicos contiene timol, carvacrol; que pertenecen al grupo funcional de los fenoles; asimismo $r$-terineno y p-cimeno que son cetonas, estos principios activos atribuyen su efectividad antibacteriana toda vez que el uso en bacterias gram negativas como Escherichia coli , Pseudomona aeruginosa, Salmonella tiphymurium, Salmonella cholerae y Vibrio cholerae han mostrado su efectividad, de igual manera podemos evidenciar estos resultados en el presente estudio frente a Porphyoromonas gingivalis que son gram negativas (11-15).

La especie Tagetes minuta (huacatay) dentro de sus compuestos químicos presenta ocimeno, cimenona, tagetona, estragol; que pertenecen al grupo funcional de los fenoles; asimismo flavonoides como quercetagetin-7-arabinosil-galactosidada, sesquiterpenos y compuestos aromáticos, estos principios activos atri- 
buyen su efectividad antibacteriana toda vez que el uso en bacterias gram negativas como Escherichia coli y Salmonella gallinarum han mostrado su efectividad, de igual manera podemos evidenciar estos resultados en el presente estudio frente a Porphyoromonas gingivalis que son gram negativas. Sin embargo es inactivo contra Lactobacillus, zymononas y especies Saccharomices, tal como se observó en nuestros resultados al mostrar inactividad frente Lactobacillus acidophilus (16-20).

En la especie Tagetes elliptica (chincho) dentro de sus compuestos químicos encontramos flavonoides,tienoles y terpenoides, estos principios activos atribuyen su efectividad antibacteriana toda vez que el uso en bacterias gram positivas como Staphylococcusaureus y gram negativas como Escherichia coli, Salmonella typhimurium han mostrado su efectividad, de igual manera podemos evidenciar estos resultados en el presente estudio frente a Lactobacillus acidphilus (gram positivo) y Porphyoromonas gingivalis que son gram negativas $(16,21-24)$.

Muchas plantas y frutos como Aloe barbadensis (aloe vera), Propolis de Apis mellífera (propóleo), Punica granatum (granada), Morinda (citrifolia), Piper cubeba (Pimienta de Java), papaína, Stryphnodendron adstringens (barbatimão); han sido sometidos a preparados hidroalcóholicos en forma de extractos naturales demostrando actividad antimicrobiana frente a diversos patógenos de la cavidad oral atribuyendo este resultados a sus principales compuestos químicos los cuales son similares a las sustancias experimentales de este estudio (Tagetes elliptica, Tagetes minuta y Origanum vulgare) (25-28).

La actividad antibacteriana del extracto etanólico del Origanum vulgare (orégano) se pudo determinar encontrando valores positivos con ambas cepas utilizando la técnica de difusión en agar pero la mínima concentración inhibitoria (MIC) no fue determinada; esto pudo deberse a múltiples variables, una de ellas la técnica de dilución, se sabe que uno de los inconvenientes de la preparación de extractos es la manipulación de los principios activos con diversos diluyentes , lo cual pudo haber afectado su actividad (29).

No se propuso como objetivo determinar la mínima concentración inhibitoria (MIC) de las sustancias experimentales frente a la cepa Porphyromonas gingi- valis ATCC 33277, toda vez que esta bacteria por ser anaerobia estricta requiere de un ambiente especializado donde la ausencia de oxígeno es el factor determinante para el crecimiento de la misma, es por eso que se sabe que la manipulación de la bacteria debe ser rápida para evitar la pérdida de esta; por ello no se realizó la técnica del MIC ya que requiere varios procedimientos y mayor tiempo de trabajo.

Los hallazgos de este estudio constituyen un aporte al conocimiento científico en el uso de plantas medicinales de aplicación odontológica ya que estas cepas bacterianas en estudio son de vital importancia en la enfermedad de caries dental y periodontal, donde la especie Lactobacillus acidophilus tiene importancia en la progresión del proceso carioso puesto que a pesar de tener poca afinidad por la superficie del diente, es uno de los primeros microorganismos en el frente de avance del proceso carioso en la dentina; su patogenicidad está relacionado a su poder acidófilo, acidúrico, acidógeno y a la síntesis de polisacáridos extra e intracelulares a partir de la sacarosa. Por otra parte la Porphyromonas gingivalis es una de las bacterias consideradas como la más patógena en la enfermedad periodontal crónica, bloquea la respuesta inflamatoria ya que no tiene la capacidad de estimular la producción de E-selectina por las células humanas dificultando de esta manera que el sistema de defensa del organismo se proteja frente a la frente a la invasión bacteriana $(16,30)$.

A pesar de nuestras limitaciones tales como ausencia de cámara de anaerobiosis para trabajar el MIC en Porphyromonas gingivalis, esta investigación es el punto de partida para que los futuros ensayos realicen la evaluación de toxicidad de los extractos estudiados, y si al comprobar que no son sustancias tóxicas se podría fomentar la formulación y elaboración de formas farmacéuticas las cuales deberán ser comprobadas con ensayos respectivos para ratificar el efecto antibacteriano con propiedades de biocompatibilidad, siendo estos productos eficaces, seguros y económicos que contribuyan a la solución de problemas de salud bucal.

\section{CONCLUSIONES}

Existe actividad antibacteriana In vitro del extracto etanólico de Origanum vulgare (orégano), Tagetes elliptica (chincho) comparado clorhexidina al 0,12\% 
y Colgate Plax frente a cepas de Lactobacillus acidophilus ATCC 43121 y Porphyromonas gingivalis ATCC 33277; asimismo el Tagetes minuta (huacatay) tiene efectividad con esta última cepa bacteriana.

La mínima concentración inhibitoria (MIC) del extracto etanólico de Tagetes elliptica (chincho) frente a Lactobacillus acidophilus ATCC 43121 es de $125 \mathrm{mg} / \mathrm{ml}$ con un halo de inhibición de $10,33 \mathrm{~mm}$.

A medida que la concentración del extracto etanólico de Origanum vulgare (orégano), Tagetes elliptica (chincho), Tagetes minuta (huacatay) disminuye, la medición de los halos de inhibición también disminuye frente a Porphyromonas gingivalis ATCC 33277. Al comparar la acción antibacteriana del Tagetes elliptica (chincho 100\%), Origanum vulgare (orégano $100 \%$ ), Tagetes minuta (huacatay $100 \%$ ) y Clorhexidina al 0,12\% frente al Lactobacillus acidophilus ATCC 43121 y Porphyromonas gingivalis ATCC 33277 se encontró diferencias estadísticamente significativas, mas no encontramos diferencias en Colgate Plax.

\section{Agradecimientos}

Al departamento de Microbiología de la Universidad Peruana Cayetano Heredia por los insumos durante la ejecución experimental. Así mismo, a la Facultad de Estomatología "Roberto Beltrán" de la Universidad Peruana Cayetano Heredia por parte del financiamiento del presente trabajo de investigación.

\section{Correspondencia:}

Erika Geovanna Pimentel Ramirez

Correo electrónico: erika.pimentel@upch.pe

\section{REFERENCIAS BIBLIOGRÁFICAS}

1. Liebana J. Microbiología Oral. 2da edición. Madrid: Mc Graw- Hill; 2002.p.345-64.

2. Liébana J, Castillo A, Álvarez M. Enfermedades periodontales: consideraciones microbiológicas. Med Oral Patol Oral Cir Bucal. 2004; 9:75-91.

3. Mujica C, Castillo M, Daille L, Fuentevilla I, Bittner M. Co-detección de patógenos periodontales en paciente chilenos con periodontitis crónica. Rev Clin Periodoncia Implantol Rehabil Oral. 2010;3(3):11822.
4. Guilart C. Bacterias Periodontopatógenas: Bacilos anerobios gran negativos como agentes etiológicos de la enfermedad periodontal. Acta odontol Venez. 2005; 43(2): 307-15.

5. Moromi H, Martinez E, Donald P. Antibacterianos naturales orales: Estudios en la Facultad de Odontología de la Universidad Nacional Mayor de San Marcos. Odontol Sanmarquina. 2009; 12(1): 25-8.

6. Matos A, Quispe S, Quito M, Beltrán S. Evaluación de la capacidad antimicrobiana del aceite esencial del orégano (Origanum vulgare) microencapsuladas en $\beta$ ciclodextrina aplicados en cultivos microbianos. Rev investig cienc tecnol aliment. 2010; 1(1): 18-23.

7. Chávez L, Díaz FM, Escalante G, Estrada E. Efecto sinérgico del aceite esencial de Origanum vulgare a la Gentamicina en cultivos de Escherichiacoli. CIMEL. 2008; 13(2): 45-8.

8. Bussmann R, Douglas S, Perez F, Díaz D. Actividad antibacteriana de plantas medicinales del norte del Perú. Tesis de Título Profesional. Iquitos, Perú: Universidad Nacional de la Amazonía Peruana; 2008. 119 pp.

9. Cáceres A. Plantas de uso medicinal en Guatemala. Guatemala: Universitaria; 1996. p.224-50.

10. Martínez J, Bernal H, Cáceres A. Fundamentos de agrotecnología de cultivo de plantas medicinales iberoamericana. Santa Fé de Bogotá: Convenio Andrés Bello;2000.p.125.

11. Albado E, Saez G, Grabiel S. Composición química $\mathrm{y}$ actividad antibacteriana del aceite esencial del Origanum vulgare (orégano). Rev Med Hered. 2001; 12: 17-9.

12. Arcila CC, Loarca G, Lecona S, González E. Orégano: Propiedades, composición y actividad biológica de sus componentes. ALAN. 2004; 54(1): 100-5.

13. Milos M, Mastelic J, Jerkovic I. Chemical composition and antioxidant effect of glycosidically bound volatile compounds from oregano (Origanum vulgare L. ssp. hirtum). Food Chem. 2000; 71(1): 79-83

14. Martínez-Domínguez M. Detección y evaluación de orégano (LippiaberlandieriShawer) en las zonas del norte de Jalisco y suroeste de Zacatecas. Tesis de Licenciatura. México DF: Universidad Autónoma Chapingo, División de Ciencias Forestales; 1990. 145 pp

15. Morales L. Estudio in vitro de la actividad antimicrobiana de los aceites esenciales de tres plantas del Perú. Tesis de Título profesional. Lima, Perú: Universidad Nacional Mayor de San Marcos, Facultad de Biología; 1995.

16. Tereschuk M, Riera M, Castro G, Abdala L. Antimicrobial activity of flavonoids from leaves of Tagetes minuta. J Ethnopharmacol. 1997; 56(3):227-32.

17. Escobar P, Herrera L, Leal S, Durán C, Stashenko E. Composición química y actividad anti-tripanosomal de aceites esenciales obtenido de Tagetes (Fam. As- 
teraceae), recolectados en Colombia. Rev Univ Ind Santander. 2009; 41(3): 280-86.

18. De las Heras B, Slowing K, Benedi J,et al. Antiinflammatory and antioxidant activity of plants used in traditional medicine in Ecuador. J Ethnopharmacol. 1998; 61: 161-6.

19. Lorenzo D, Loayza I, Dellacassa E. Composition of the essential oil of Tagetes maxima Kuntze from Bolivia. Fragr Flavour J. 2002; 17: 115-8.

20. Singh S, Sharma P, Vats L. Light dependent toxicity of the extract of plant Tagetes erecta and $\alpha$-terthienyl toward larvae of mosquito Culextritaeniorhynchus. Toxicol Environm Chem. 1987; 16(1): 81-8.

21. Pineda C, Camiloaga E, Zuñiga S. Actividad antimicrobiana del extracto de hojas de Chincho (Tagetes elliptica L.) contra Salmonella typhimurium en cobayos (Cavia porcellus L). Investigación Valdizana. 2007; 1(1): 10-13.

22. Parejo I, Bastida J, Viladomat F, Codina C. Acylatedquercetagetin glycosides with antioxidant activity from Tagetes máxima. Phytochemistry. 2005; 66: 2356-62.

23. Beltrán H, Granda A, León B, Sagástegui A, Sánchez I, Zapata M. Asteraceae endémicas del Perú. Rev peru biol. 2006; 13(2): 64-9.

24. Visintin A, Bernardello G. Morfología y Anatomía floral de Tagetes minuta L. (Asteraceae). ArnaldoA. 2005;12(1-2):8-15.

25. Bhardwaj A, Ballal S, Velmurugan N. Comparative evaluation of theantimicrobialactivity of natural extracts of Morindacitrifolia, papain and aloe vera(all in gel formulation), $2 \%$ chlorhexidine gel and calcium hydroxide, against Enterococcus faecalis: An in vitro study. J Conserv Dent. 2012; 15(3):293-7.

26. Mayta-Tovalino F, Sacsaquispe -Contreras SJ. Evaluación in vitro del efecto antibacteriano del extracto etanólico de propóleo de Oxapampa-Perú sobre cultivos de Streptococcusmutans(ATCC 25175) y Staphylococcusaureus (ATCC 25923). Rev Estomatol Herediana. 2010; 20 (1): 19-24.

27. Aneja K, Joshi R, Sharma C, Aneja A. Antimicrobial efficacy of fruit extracts of two Piper species against selected bacterial and oral fungal pathogens. Braz J Oral Sci. 2010; 9(4):421-6.

28. Pimenta S. Atividade antibacteriana do extrato hidroalcoólico bruto de Stryphnodendron adstringens sobre microorganismos da cárie dental. Rev odonto ciênc. 2008;23(2):141-144.

29. Kuklinski C. Farmacognosia: Estudio de las drogas y sustancias medicamentosas de origen natural. Barcelona: Omega ediciones; 2003. p. 134-43.

30. Ulloa C. Aromas y sabores andinos. En: Moraes M, Ollgaard B, Kvist LP, Borchsenius F, Balslev H. Botánica económica de los andes centrales. La Paz, Bolivia: Plural Editores; 2006. p. 313-28.

Recibido : 05/03/2015

Aceptado: 20/06/2015 